\title{
Tensile properties of very-high-strength concrete for penetration-resistant structures
}

\author{
E.F. O'Neil ${ }^{\mathrm{a}, *}$, B.D. Neeley ${ }^{\mathrm{a}}$ and J.D. Cargile ${ }^{\mathrm{b}}$ \\ ${ }^{\mathrm{a}}$ Concrete and Materials Division, Structures \\ Laboratory, US Army Engineer Research and \\ Development Center, 3909 Halls Ferry Road, \\ Vicksburg, MS 39180-6199, USA \\ ${ }^{\mathrm{b}}$ Geomechanics and Explosion Effects Division, \\ Structures Laboratory, US Army Engineer Research \\ and Development Center, 3909 Halls Ferry Road, \\ Vicksburg, MS 39180-6199, USA
}

Received 7 March 1997

Revised 24 August 1999

This paper describes the potential suitability of a new family of concrete mixtures for use in protective structures. Two very-high-strength concrete mixtures are discussed and experimental results of penetration studies on one of these are presented. The results are compared to penetration-study results of other, more conventional concrete mixtures, and the advantages of the very-high-strength mixtures are described.

\section{Introduction}

Concrete is generally considered to be a proper construction material for many civil and military applications. It can be strong and produced to be durable, it can be placed in many shapes, and is economical. It is primarily used for its compressive strength since it is much stronger in compression than it is in tension; but with the proper use of tensile reinforcement it is commonly used in many applications where tensile strength is needed such as in flexural members, eccentrically-loaded compression members, and direct tension members.

The mass of a concrete member can be increased or decreased by altering its component materials and its geometry. For applications where mass is important, a large section of normal-density concrete or a smaller section of high-density concrete can be used.

\footnotetext{
${ }^{*}$ Corresponding author.
}

For applications where mass or size is detrimental, yet strength is necessary, concrete structures are often designed to provide thin sections of higher-strength concrete. In other applications, the combination of high strength and high mass, or high strength and low mass are important and often critical criteria. The strength and mass of a concrete section is important in applications where concrete is being considered as a material for use in protective structures.

Engineers are constantly looking for new materials to provide answers to complex problems. As construction and material costs escalate, demand has increased for stronger materials that occupy less space. Recently, research has been directed towards using high-performance concrete materials to solve problems in providing protective structures $[6,12,13,15]$.

Recent developments of very-high-strength concrete $[8,14,16-18]$ made using conventional constituents combined in critical proportions have further expanded these capabilities. This paper describes the potential suitability of a new family of concrete mixtures for use in protective structures.

\section{Limitations of conventional concrete}

Unreinforced concrete is inherently brittle, it has very little capacity for inelastic deformation before failure, and is weak in tensile load-carrying capacity. Under compressive loading, it has an approximately linear stress-strain history until initiation of first cracking of its matrix. As loading continues above this point the material exhibits increased non-linear strain per unit stress for a short time before ultimately failing in a brittle manner.

The unconfined compressive strength of conventional concrete is generally less than $40 \mathrm{MPa}$. Concretes with design strength in compression of $41.4 \mathrm{MPa}$ or greater are called "high-strength". High-strength concrete having design compressive strength of 100 to $125 \mathrm{MPa}$ is available in many areas. The tensile strength of most concrete generally does not exceed 
$10 \%$ of the compressive strength, i.e., approximately 4 to $10 \mathrm{MPa}$. However, the tensile strength of veryhigh-strength concrete does not follow this proportional relationship. The tensile strength in very-highstrength concrete often is no higher than $10 \mathrm{MPa}$ as in the conventional high-strength concrete. For use as a protective material, both tensile and compressive strength are important properties. From a ballistic point of view, they are important in resisting the cratering and break-up of the structure caused by projectile penetration.

Two new concrets have the potential for increased penetration resistance. The first, Reactive Powder Concrete (RPC), was developed in France [7,20] and is a successor to concrete materials developed in the early eighties known as macro-defect-free (MDF) concrete $[3,4]$ and densified with small particles (DSP) concrete [2]. The second material, very-high-strength concrete (VHSC), was developed by the U.S. Army Engineer Waterways Experiment Station (WES) as a concrete for use in protective structures [14]. These two concretes consist of only fine materials. Aggregate size is limited to a maximum of $0.4 \mathrm{~mm}$ in the RPC and $4.75 \mathrm{~mm}$ in the VHSC. A description of these two concretes follows, as well as a discussion of penetration experiments of a VHSC mixture.

\section{RPC and VHSC principles}

RPC and VHSC are made from the same general component constituents as conventional concrete (cementitious material, water, aggregate, and admixtures). Yet, the careful selection of constituents and their proportions, as well as proper mixing, results in significantly improved properties. These properties include: tensile and compressive strength, permeability, toughness, and durability. Their physical and mechanical properties can be further improved by the application of heat and pressure during the casting and curing stages of hydration. Some significant differences from conventional and high-strength concrete are

(1) size and composition of constituents,

(2) water to cementitious material ratio $(\mathrm{w} / \mathrm{cm})$,

(3) the use of steel fibers (sometimes micro-fibers) to improve ductility and toughness,

(4) the amount of mixing energy employed, and

(5) curing procedures.
Table 1

Principles of RPC and VHSC

- Improved homogeneity through particle size and material selection.

- Increased density by optimization of particle size and mixing technology.

- Improved strength by maximizing reactive materials and minimizing water content.

- Increased microstructure by application of pressure before setting and post-set heat treatment.

- Increased tensile strength, toughness, and ductility by incorporation of steel fibers or steel micro-fibers.

The principles used in producing RPC and VHSC are listed in Table 1.

Conventional concrete is a very heterogeneous material with components from fine cement to coarse aggregate each exhibiting different strengths and modulii of elasticity. Under a system of forces, all these component materials deform at different rates. The differential movement of these components produce strains between the component materials which begin the process of tensile fracture when the strains exceed the tensile strain capacity of the concrete. Concrete such as RPC and VHSC is composed of particles of similar modulii and size which helps increase the homogeneity of the composite material thereby reducing the differential tensile strain in the concrete and increases the ultimate load-carrying capacity of the material.

High density ${ }^{1}$ is the second principle employed to increase strength and decrease permeability. In choosing the volumes of component materials, particlepacking techniques can be used to maximize the amount of solids per unit volume of concrete. As with conventional concrete, the material having the largest particle size in RPC and VHSC is the aggregate, which in both materials is the sand. The material having the next largest particle size is the cement, which is on the order of 10 to $100 \mu \mathrm{m}$. The smallest particles are silica fume, which are on the order of $0.1 \mu \mathrm{m}$ in diameter. The component volumes of all these particles are chosen to achieve the greatest particle packing and hence the greatest density of the paste. The higher the density the greater the strength of the paste and the lower the permeability because there are fewer and smaller voids.

Strength of RPC and VHSC is further improved by increasing the volume of pozzolanic components

\footnotetext{
${ }^{1}$ In this discussion density (or in some contexts "denseness") means the relative amount of volume in the freshly mixed product occupied by solid particles not the mass per unit volume of the product.
} 
which can react to form hydration products. In RPC, as well as in VHSC, materials with a high silica content are necessary for optimum performance. Cements which are high in silica content produce higher strengths. Large volumes of low-carbon silica fume [14] also enhance the production of strength. These materials provide chemically active silica which helps to produce larger volumes of calcium-silicate-hydrate $(\mathrm{CSH})$, the binder that cements the other component material together. High amounts of CSH increase the strength of the binder and improve the bond between the cement and the aggregate.

To optimize performance, w/cm in RPC and VHSC must be held to a minimum. Excess water in the mixture is detrimental to the strength of concrete. The quantity of water required to hydrate all of a given amount of portland cement is about that present at a w/c of 0.4 . Water that is not chemically or physically combined in the hydration or pozzolanic reaction products weakens the paste and thus the compressive and tensile strength of the concrete. The volume of water used in RPC and VHSC is kept low to insure that there is no excess. This volume is less than that needed to hydrate all the cement so as to insure that all water is consumed in the hydration/pozzolanic reaction process. However, this small quantity of water usually does not provide sufficient workability to the mixture. High-range-water-reducing admixtures (HRWRA) are used to make the, otherwise very stiff, concrete flowable.

All these mixture principles combine to produce concrete with an ultimate compressive strength up to approximately $175 \mathrm{MPa}$ when mixed and cured at ambient temperatures. Strength greater than $200 \mathrm{MPa}$ can be achieved when the concrete is cured at $90{ }^{\circ} \mathrm{C}$ for a few days. The processes of adding pressure sufficient to expel any excess liquids and air from the fresh mixture during the casting operations, and providing a curing environment of up to $400^{\circ} \mathrm{C}$ can produce concrete with compressive strength greater than $800 \mathrm{MPa}$.

\section{Tensile properties}

The tensile strength of the RPC and VHSC concretes is higher than that of conventional concretes. The direct tensile strength of VHSC may only be $10 \mathrm{MPa}$ when its compressive strength is on the order of $180 \mathrm{MPa}$. However, the addition of steel fibers increases the firstcrack load, increases the ultimate load-bearing capacity, and dramatically increases the flexural toughness.
These ultra-high-strength concretes, RPC in particular, have stress-strain characteristics which are nearly linearly elastic to failure when fabricated without the addition of fibers. Their fracture energy, defined as the area beneath the load-deflection curve, is somewhat less than $140 \mathrm{~J} / \mathrm{m}^{2}$. The addition of fibers to the matrix improves the behavior of the concrete in the post-first-crack region of the load-to-failure cycle. In RPC, straight, high-strength, steel, micro-fibers $13 \mathrm{~mm}$ in length and $0.16 \mathrm{~mm}$ in diameter are added to the matrix in amounts ranging from 1.5 to $3.0 \%$ by volume. In VHSC, various percentages and types of steel fibers have been used but the best overall results have been obtained with hooked-ended, steel fibers $30 \mathrm{~mm}$ in length and $0.5 \mathrm{~mm}$ in diameter.

The large number of small fibers which cross the path of potential cracks, coupled with the good bond between fiber and matrix provides high resistance to fiber pullout during tensile-cracking, and greatly increase the toughness of the material. Figure 1 shows the load-deflection curve of a typical RPC or VHSC beam. By comparison, a load-deflection curve for a conventional concrete and a conventional fiberreinforced concrete are added. Comparison of the areas under the curves gives a relative relationship for the increase in toughness afforded by the very-highstrength concrete. The greatest effect is in the area of the curve beyond the first-crack load. Up until this load, the tensile-carrying-capacity of the concrete has been responsible for the shape of the curve. In the unreinforced concrete the magnitude of the first-crack load is about one-tenth that of the VHSC and RPC and the load and deflection of the post-first-crack portion of the curve is very small. Likewise, even with conventional fiber-reinforced concrete the first-crack strength is lower than RPC and VHSC and the post-first-crack portion of the curve is also smaller.

Toughness is a measure of the amount of energy which must be expended to open cracks in the matrix under tensile loading. An example of toughness would be the resistance to a projectile passing through a material. The toughness of RPC has been measured at $40000 \mathrm{~J} / \mathrm{m}^{2}$ or greater than 250 times the toughness of conventional concrete [19]. This toughness is important in the performance of protective structures. The amount of energy required to penetrate the VHSC or RPC concrete will be greater than that required to penetrate conventional concrete. This will mean that some projectiles will be less effective and perhaps will be stopped by the high-performance concrete. If the projectile completely passes through the very-high- 


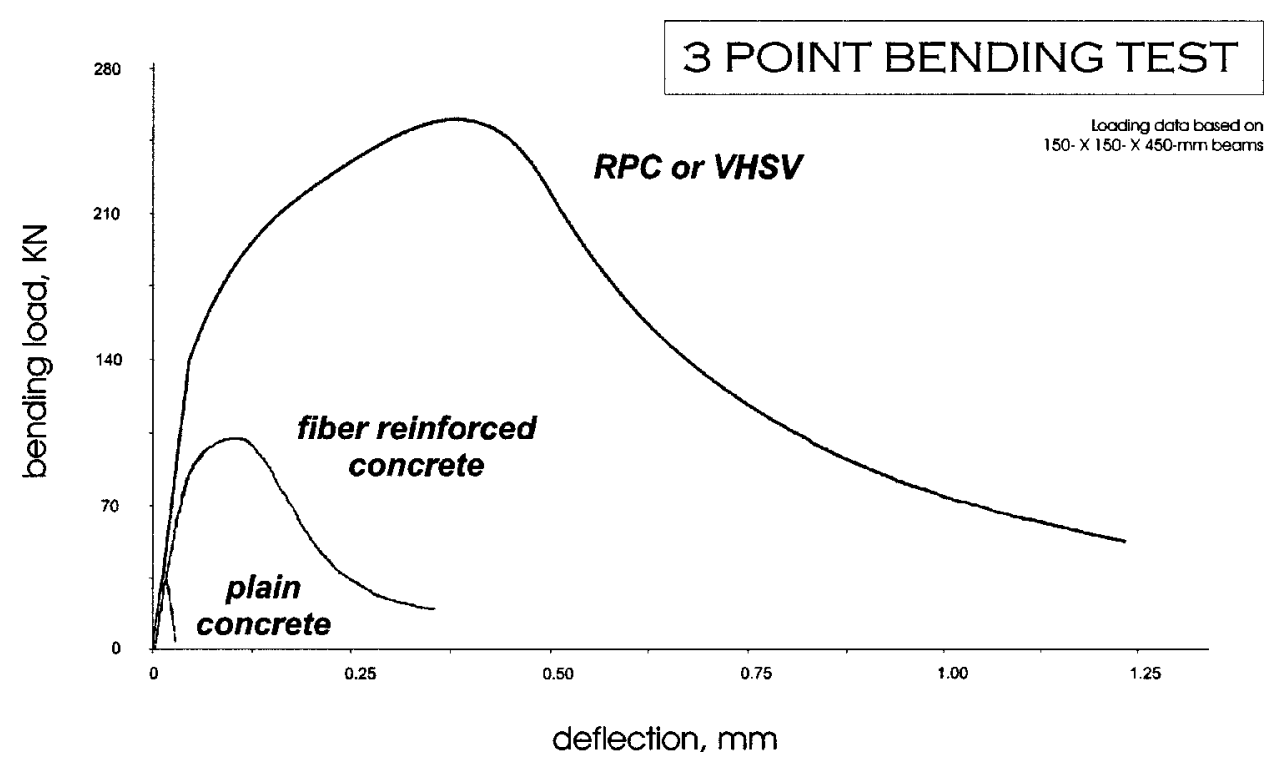

Fig. 1. Comparative flexural-toughness curves of VHSC concretes with plain and fiber-reinforced concrete.

Table 2

Concrete mixture proportions $\left(\mathrm{kg} / \mathrm{m}^{3}\right)$

\begin{tabular}{lccccc}
\hline Material & CSPC & HSPC & HSFR & RPC & VHSC $^{*}$ \\
\hline Type I Portland Cement & 328 & 546 & 459 & 942 & 24 \\
Silica Fume, silica & 0 & 71 & 59 & 236 & $13^{* *}$ \\
Class F Fly ash & 0 & 119 & 59 & 0 & 0 \\
Coarse Aggregate & 1034 & 817 & 520 & 0 & 0 \\
Sand & 806 & 0 & 451 & $1036^{\dagger}$ & 0 \\
Limestone Fine Agg. & 0 & 657 & 469 & 0 & 40 \\
Water & 187 & 166 & 171 & 136 & 17 \\
Water Reducing Adm. & $1.7^{\dagger \dagger}$ & 0 & 0 & 0 & 0 \\
HRWRA & 0 & 12 & 6 & 41 & 3 \\
Air Detraining Adm. & 0.3 & 1 & 0.6 & 0 & 0 \\
w/cm & 0.57 & 0.22 & 0.3 & 0.12 & 0.18 \\
Fibers & 0 & 0 & 158 & 160 & 3 \\
\hline
\end{tabular}

*Mixture proportions to VHSC are given in \% by volume.

$* * 8 \%$ of addition is silica fume and $5 \%$ is silica flour (crushed quartz).

${ }^{\dagger}$ RPC fine aggregate was $100 \%$ manufactured quartz sand.

$\dagger \dagger$ Water reducing admixture given in $1 / \mathrm{m}^{3}$.

performance concrete, the exit velocity will be lower than that through the same mass of conventional concrete. Also, material scabbed from the back face of a protective-structure member will be reduced by the steel fibers in the matrix.

\section{Penetration experiments}

Normal impact depth-of-penetration versus striking velocity experiments were conducted into targets fabri- cated using the VHSC concrete. The experiments were used to evaluate the resistance of VHSC to penetration by low explosive charge-to-mass projectiles. VHSC mixture proportions are given in Table 2. The concrete for the targets was placed into corrugated, galvanizedsteel culverts measuring approximately $762 \mathrm{~mm}$ in diameter by $914 \mathrm{~mm}$ in length. The thickness of the steel was $3 \mathrm{~mm}$. The culverts were insulated with a $50-\mathrm{mm}$ thick layer of batt fiberglass insulation around their circumference and the open tops of the culverts were fitted with foam insulation to maintain heat during cur- 
ing. Curing of the targets consisted of ponding water on the cast specimens under ambient temperature conditions for 7 days and then continuing the curing in ambient air conditions until the time of the penetration experiments. At the time of target fabrication, 102mm-diameter by 203-mm-long cylinders were molded for unconfined-compressive-strength tests. The penetration experiments and unconfined-compression tests were conducted on approximately the same day. The age of the concrete at the time of the penetration experiments ranged from 30 to 60 days.

The $0.906-\mathrm{kg}$ projectiles were machined from 4340 steel rods and heat treated to a hardness of $R_{\mathrm{c}} 43-45$. Each projectile had an ogive nose with a caliber-radiushead of 2.0, a shank diameter of $26.9 \mathrm{~mm}$ and an overall length of $242.4 \mathrm{~mm}$ as shown in Fig. 2. In general, a target-diameter to projectile-diameter ratio of at least

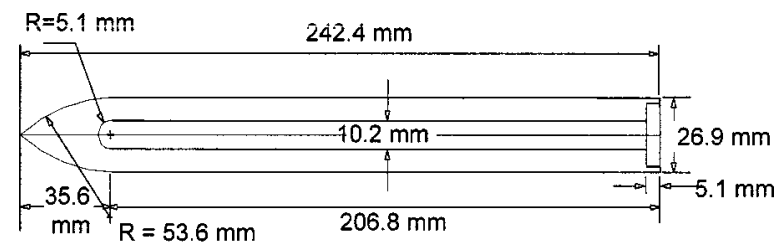

Case Material: $\mathbf{4 3 4 0}$

Mass: $0.906 \mathrm{~kg}$

CG Location: $128.5 \mathrm{~mm}$ from nose

Fig. 2. Drawing of armor-piercing projectile.
25 is desired to avoid significant edge effects during penetration. Large cracks that may develop in a target that is too small for the projectile being launched into it can result in increased depth of penetration and turning of the projectile. The target-diameter to projectilediameter for these experiments is approximately 28 .

At the time of the penetration experiments, the targets were placed on their sides, still in the metalculvert forms, with the top face as placed perpendicular to and centered on the longitudinal axis of the gun. They were strapped to a carriage that can allow late-event, post-test, longitudinal movement and which prevents any rotation of the target off the longitudinal axis. The projectiles were launched into the targets using the WES 83-mm, smooth-bore powder gun [11] at striking velocities $\left(V_{\mathrm{s}}\right)$ ranging from $229 \mathrm{~m} / \mathrm{s}$ to $754 \mathrm{~m} / \mathrm{s}$. The projectiles were fitted with plastic sabots and obturators that fit snugly into the gun bore. Sabots and obturators were stripped aerodynamically prior to the projectile striking the target. Striking velocities were measured from orthogonal views captured using a streak camera. Pitch and yaw were measured from flash X-rays taken just prior to target impact. Results from the experiments are summarized in Table 4.

Depth of penetration $(P)$ in calibers (penetration depth/projectile diameter) for the experiments into VHSC concrete are compared to results from penetration experiments into a conventional-strength portland cement (CSPC) concrete [10], high-strength portland

Table 3

Hardened material properties

\begin{tabular}{lcccc}
\hline & CSPC & HSPC & HSFR & VHSC \\
\hline 28-day compressive strength (MPa) & 35 & 104 & 85 & 157 \\
Compressive modulus of elasticity $(\mathrm{GPa})$ & 34.5 & 45.2 & 45.2 & 46 \\
56-day tensile strength (MPa) & 3.5 & 4.8 & 4.5 & 9.0 \\
Tensile modulus of elasticity (GPa) & 44 & 39.5 & 39.6 & - \\
\hline
\end{tabular}

Table 4

Summary of results from penetration experiments

\begin{tabular}{lcllccc}
\hline $\begin{array}{l}\text { Shot } \\
\text { number }\end{array}$ & $\begin{array}{c}\text { Impact } \\
\text { velocity, } \\
V_{\mathrm{s}}(\mathrm{m} / \mathrm{s})\end{array}$ & $\begin{array}{c}\text { Pitch } \\
\text { (degrees) }\end{array}$ & $\begin{array}{c}\text { Yaw } \\
\text { (degrees) }\end{array}$ & $\begin{array}{c}\text { Penetration } \\
\text { depth, } P \\
\text { (calibers) }\end{array}$ & $\begin{array}{c}\text { Concrete } \\
\text { strength } \\
(\mathrm{MPa})\end{array}$ & $\begin{array}{c}\text { Projectile } \\
\text { mass (kg) }\end{array}$ \\
\hline 1 & 406 & 0.8 up & 0.6 left & 6.7 & 159 & 0.902 \\
2 & 587 & 0.4 down & 3.6 left & 11.0 & 157 & 0.902 \\
3 & 287 & 0.4 up & 0.9 right & 4.9 & 162 & 0.904 \\
4 & 747 & 0.1 up & 2.6 left & 16.5 & 160 & 0.903 \\
5 & 573 & 0.2 up & 3.1 left & 10.9 & 160 & 0.904 \\
6 & 754 & 1.3 down & 1.8 left & 17.1 & 155 & 0.904 \\
7 & 397 & 0.1 up & 0.7 left & 6.0 & 163 & 0.907 \\
8 & 229 & 0.9 up & 0.6 right & 3.0 & 157 & 0.905 \\
\hline
\end{tabular}




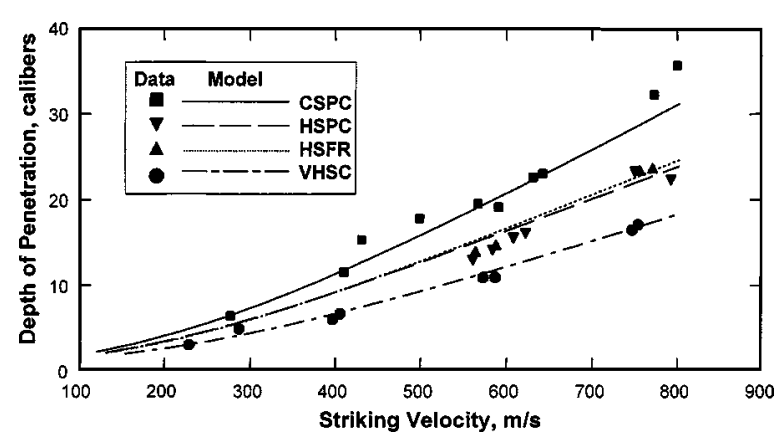

Fig. 3. Comparison of results from penetration experiments into CSPC, HSPC, HSFR, and VHSC concretes and spherical-cavity expansion model calculations.

cement (HSPC) concrete [10], and high-strength, steelfiber reinforced (HSFR) concrete [5] in Fig. 3. The experiments into the CSPC, HSPC, and HSFR concretes used projectiles with the same mass and dimensions as the projectile used for the experiments into the VHSC concrete. Target fabrication for the CSPC, HSPC, and HSFR experiments was similar to that for the VHSC concrete except that the targets were approximately $1.37 \mathrm{~m}$ in diameter. Penetration experiments were conducted into the HSPC and HSFR targets at approximately 60 days age and the CSPC targets at approximately 30 days age. The average unconfined compressive strength of the VHSC, CSPC, HSPC, and HSFR concretes used to fabricate targets in these tests is 159 , 35, 104, and $90 \mathrm{MPa}$, respectively. Typical compressive strength values for VHSC can be higher, on the order of $185 \mathrm{MPa}$, depending on the materials and processing used. Additional material property data are presented in Table 3.

The depth of penetration from experiments into the HSPC and HSFR concretes is about $30 \%$ less than that from experiments into the CSPC concrete. The depth of penetration from experiments into the VHSC concrete is about $50 \%$ less than that from experiments into the CSPC concrete. Post-test photographs of the target faces in Fig. 4 show the visible damage to the targets for experiments at a striking velocity of about $800 \mathrm{~m} / \mathrm{s}$. The amount of visible damage to the HSPC concrete target is about the same as that for the CSPC concrete target, even though the depth of penetration is about $30 \%$ less. The addition of steel fibers in the HSFR concrete resulted in a significant decrease in visible damage, and still resulted in a depth of penetration about $30 \%$ less than the CSPC concrete. The visible damage to the VHSC concrete target is comparable to the damage to the HSFR concrete target.
Also in Fig. 3, results from the penetration experiments are compared to depth of penetration calculated using the spherical-cavity expansion model presented by Forrestal and Tzou [9]. One model presented in their paper, and shown in Fig. 3, separates the target response into elastic, cracked, and plastic (EKP) regions, with the plastic region being closest to the projectile. The target is described by density, yield strength, slope of the yield surface, tensile strength, and linear bulk modulus. The tensile strength of the material determines the influence of the cracked region on the depth of penetration. Values for these model parameters were determined for each concrete based on data contained in references $[1,12,15]$. The volumetric response (bulk modulus), yield strength, and yield surface used to describe each material are presented in Figs 5 and 6, respectively. These figures contain an interpretation of the data found in the references for use in the cavity-expansion model. The tensile strength used in the model is a percentage of the yield strength based on the ratio between the directpull tensile strength and compressive strength for each concrete $(0.10,0.0275,0.05$, and 0.05 for the CSPC, HSPC, HSFR, and VHSC concretes, respectively). The results from the cavity-expansion calculations agree well with the experiment results (see Fig. 3). Another model presented in the paper by Forrestal and Tzou separates the target response into elastic and plastic (EP) regions. This model was used to illustrate the influence of the cracked region on the depth of penetration. Results from the two models are compared in Fig. 7. Use of the EP model results in less depth of penetration than the results from the EKP model. The influence of the cracked region is greatest for the higherstrength concretes. Results from the calculation using the EP model represent a limit to the depth of penetration that could be expected as the tensile-yield strength approaches the compressive-yield strength.

\section{Conclusions}

Development of a new class of very-high-strength concretes based on use of small-particle component materials and particle-packing theories has led to a material with improved penetration resistance. The compressive strength of these concretes is very high, being approximately $200 \mathrm{MPa}$ and the direct-tensile strength approximately $10 \mathrm{MPa}$. Additionally, the flexural toughness of the concrete is greater than 250 times that of conventional, non-fiber-reinforced concrete. 


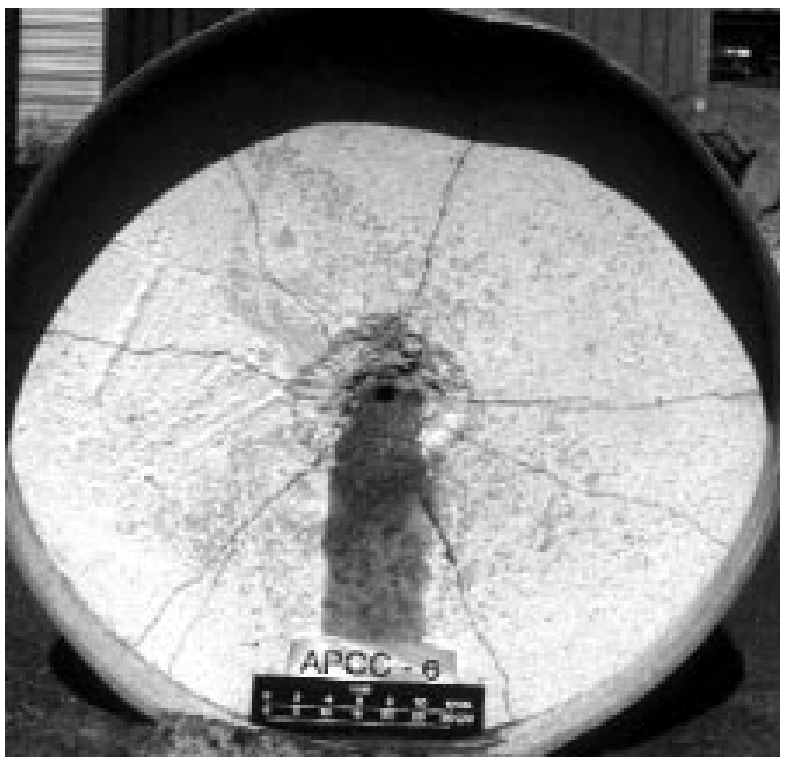

(a)

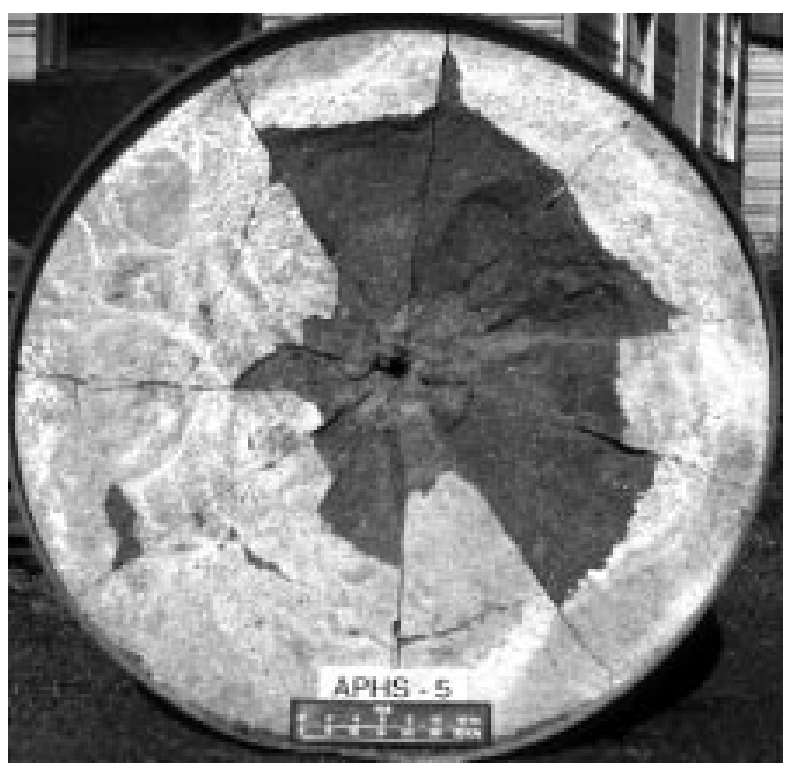

(b)

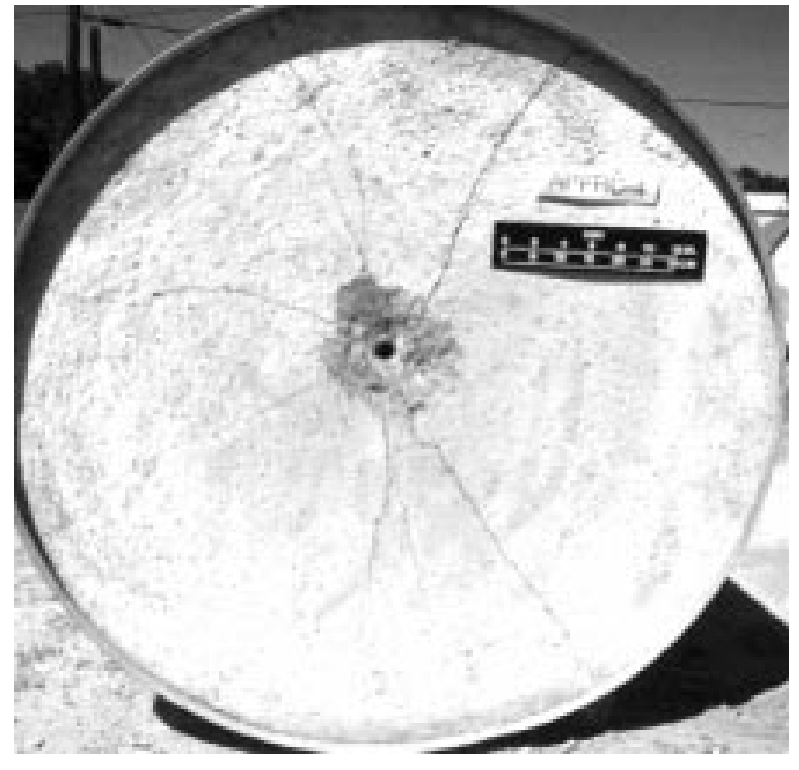

(c)

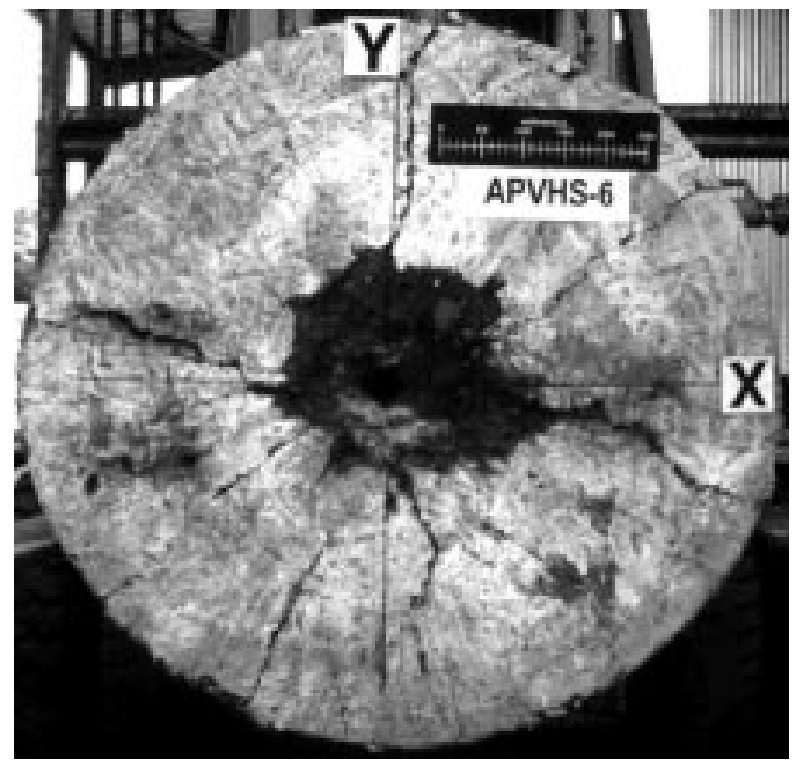

(d)

Fig. 4. Front-face damage to targets impacted at approximately $800 \mathrm{~m} / \mathrm{s}$. (a) CSPC concrete, (b) HSPC concrete, (c) HSFR concrete, (d) VHSC concrete.

Penetration-resistance experiments were conducted on the VHSC concrete in this study and were compared with penetration results for other concrete materials. Impact into the VHSC concrete resulted in approximately $50 \%$ less penetration than into CSPC concrete, and $30 \%$ less penetration than into HSPC and HSFR concrete. Inclusion of fibers into these concretes does not significantly improve the penetration resistance of a given strength of concrete, but does provide for greater resistance to visible damage to the concrete surrounding the penetration crater. Results from calculations using spherical-cavity expansion model with elastic-cracked-plastic regions agreed well with the experimental results. 


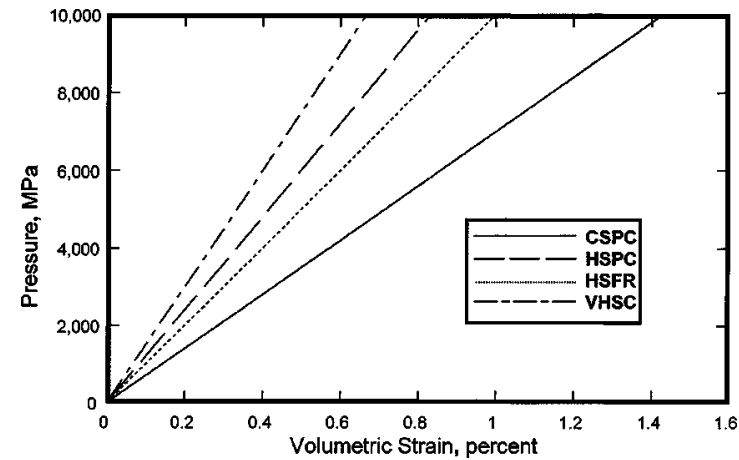

Fig. 5. Pressure-volumetric strain responses used in the spherical-cavity expansion model for the CSPC, HSPC, HSFR, and VHSC concretes.

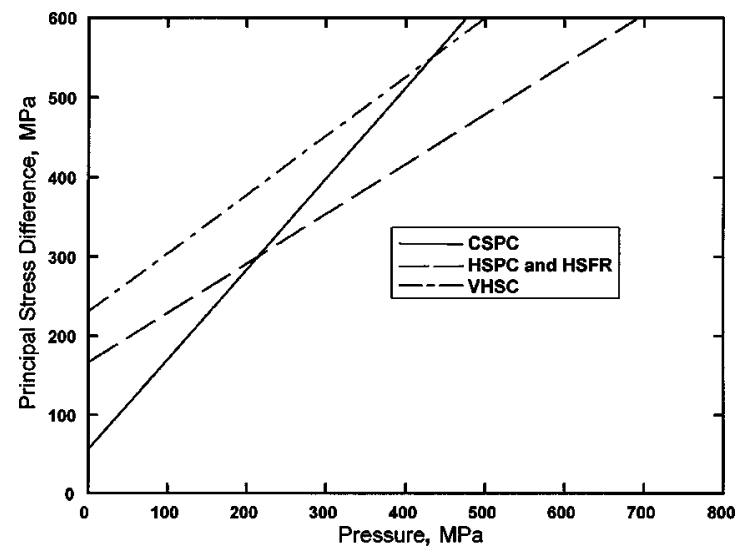

Fig. 6. Yield surfaces used in the spherical-cavity expansion model for the CSPC, HSPC, HSFR, and VHSC concretes.

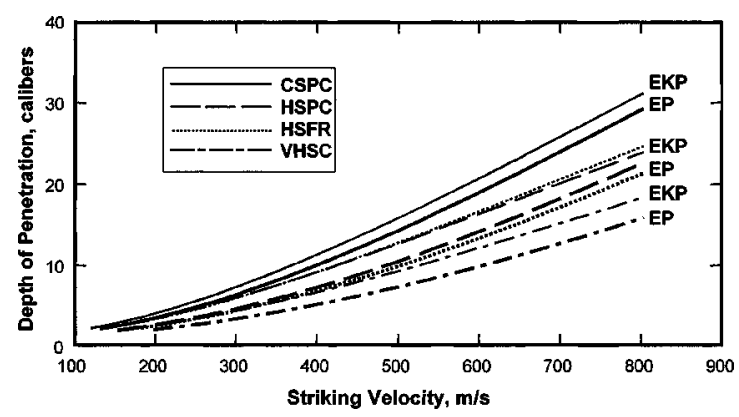

Fig. 7. Comparison of calculations using the elastic-cracked-plastic (EKP) and elastic-plastic (EP) versions of the spherical-cavity expansion model.

\section{Acknowledgements}

The tests described and the resulting data presented herein, unless otherwise noted, were obtained from research conducted under the Hardened Construction
Materials Work Package of the United States Army Corps of Engineers by the Waterways Experiment Station. The permission from the Headquarters, U.S. Army Corps of Engineers, to publish this paper is gratefully acknowledged.

\section{References}

[1] S.A. Akers, M.L. Green and P.A. Reed, Laboratory characterization of very high-strength fiber-reinforced concrete. Technical report SL-98-10, U.S. Army Engineer Waterways Experiment Station, Vicksburg, MS, 1998.

[2] H.H. Bache, Densified cement/ultrafine particle-based materials. CBL report No. 40, Aalborg Portland A/S, Aalborg, Denmark, 33 pp.

[3] J.D. Birchall, A.J. Howard and K. Kendall, Flexural strength and porosity of cements, Nature 289(5796) (1981), 388-390.

[4] J.D. Birchall, A.J. Howard and K. Kendall, A cement spring, J. of Materials Science Letters 1 (1982), 125-126.

[5] J.D. Cargile, unpublished experimental results. U.S. Army Engineer Waterways Experiment Station, Geomechanics and Explosion Effects Division, Structures Laboratory, 1998.

[6] J.D. Cargile and L.E. Tidwell, Penetration of a subscale semi-armor-piercing projectile into conventional-strength and high-strength concrete targets. Technical report SL-93-2, U.S. Army Engineer Waterways Experiment Station, Vicksburg, MS, 1993.

[7] M. Cheyrezy, V. Maret and L. Frouin, Microstructural analysis of RPC (Reactive Powder Concrete), Cement and Concrete Research 25(7) (1995), 1491-1500.

[8] W.M. Dowd and E.F. O'Neil, Development of reactive powder concrete (RPC) precast products for the USA market, in: Proc., 4th Int. Symposium on the Utilization of High-Strength/HighPerformance Concrete, F. de Larrard and R. Lacroix, eds, Presses de l'École Nationale des Ponts et Chaussées, Paris, France, May 29-31, 1996, pp. 1391-1398.

[9] M.J. Forrestal and D.Y. Tzou, A spherical cavity-expansion penetration model for concrete targets, Int. J. of Solids and Structures 34(31/32) (1997), 4127-4146.

[10] M.J. Forrestal, B.S. Altman, J.D. Cargile and S.J. Hanchak, An empirical equation for penetration depth of ogive-nose projectiles into concrete targets, Int. J. of Impact Engineering 15(4) (1994), 395-405.

[11] D.J. Frew, J.D. Cargile and J.Q. Ehrgott, WES geodynamics and projectile penetration research facilities, in: Proc. Advances in Numerical simulation Techniques for Penetration and Perforation of Solids, E.P. Chen and V.K. Luk, eds, American Society of Mechanical Engineers, New Orleans, LA, ASME Winter Annual Meeting, 28 November-3 December 1993, pp. 1-8.

[12] M.I. Hammons, B.D. Neeley and D.M. Smith, Development and characterization of fiber-reinforced and slag-binder concrete mixtures for projectile-penetration studies. Technical report SL-92-16, U.S. Army Engineer Waterways Experiment Station, Vicksburg, MS, 1992. 
[13] B.D. Neeley and D.J. Frew, Development and characterization of a high-strength, high-density nylon fiber reinforced and slurry-infiltrated-mat concrete for projectile penetration studies. Technical report SL-95-17, U.S. Army Engineer Waterways Experiment Station, Vicksburg, MS, 1995.

[14] B.D. Neeley and D.M. Walley, VHS Concrete, The Military Engineer 87(572) (1995), 36-37.

[15] B.D. Neeley, M.I. Hammons and D.M Smith, Development and characterization of conventional strength and high-strength portland cement concrete mixtures for projectile penetration studies. Technical report SL-91-15, U.S. Army Engineer Waterways Experiment Station, Vicksburg, MS, 1991.

[16] E.F. O'Neil, Reactive powder concrete: A very-highperformance concrete material, in: Proc. Conf. Corps of Engineers Structural Engineering, H.W. Jones and B.D. Fehl, eds, U.S. Army Corps of Engineers, Engineering and Construction Directorate, San Antonio, TX, August 28-30, 1995, pp. 11951204.
[17] E. F. O'Neil and W. M. Dowd, Reactive powder concrete: A new material for the construction industry, in: Proc. $3 r d ~ N a-$ tional Conf. Concrete and Masonry Engineering, S.K. Ghosh, ed., San Francisco, CA, June 15-17, 1995, pp. 43-50.

[18] E.F. O'Neil, C.E. Dauriac and S.K. Gilliland, Development of reactive powder concrete (RPC) products in the United States construction market, in: High-Strength Concrete: An International Perspective, ACI SP-167, J.A. Bickley, ed., American Concrete Institute, Farmington Hills, MI, November 1995, pp. 249-262.

[19] P. Richard and M. Cheyrezy, Reactive powder concretes with high ductility and 200-800 MPa compressive strength, in: Proc. of V. Mohan Malhotra Symposium Concrete Technology Past, Present, and Future, ACI SP-144, P.K. Mehta, ed., American Concrete Institute, Farmington Hills, MI, March 1994, pp. 507-518.

[20] P. Richard and M. Cheyrezy, Composition of reactive powder concretes, Cement and Concrete Research 25(7) (1995), 15011511. 

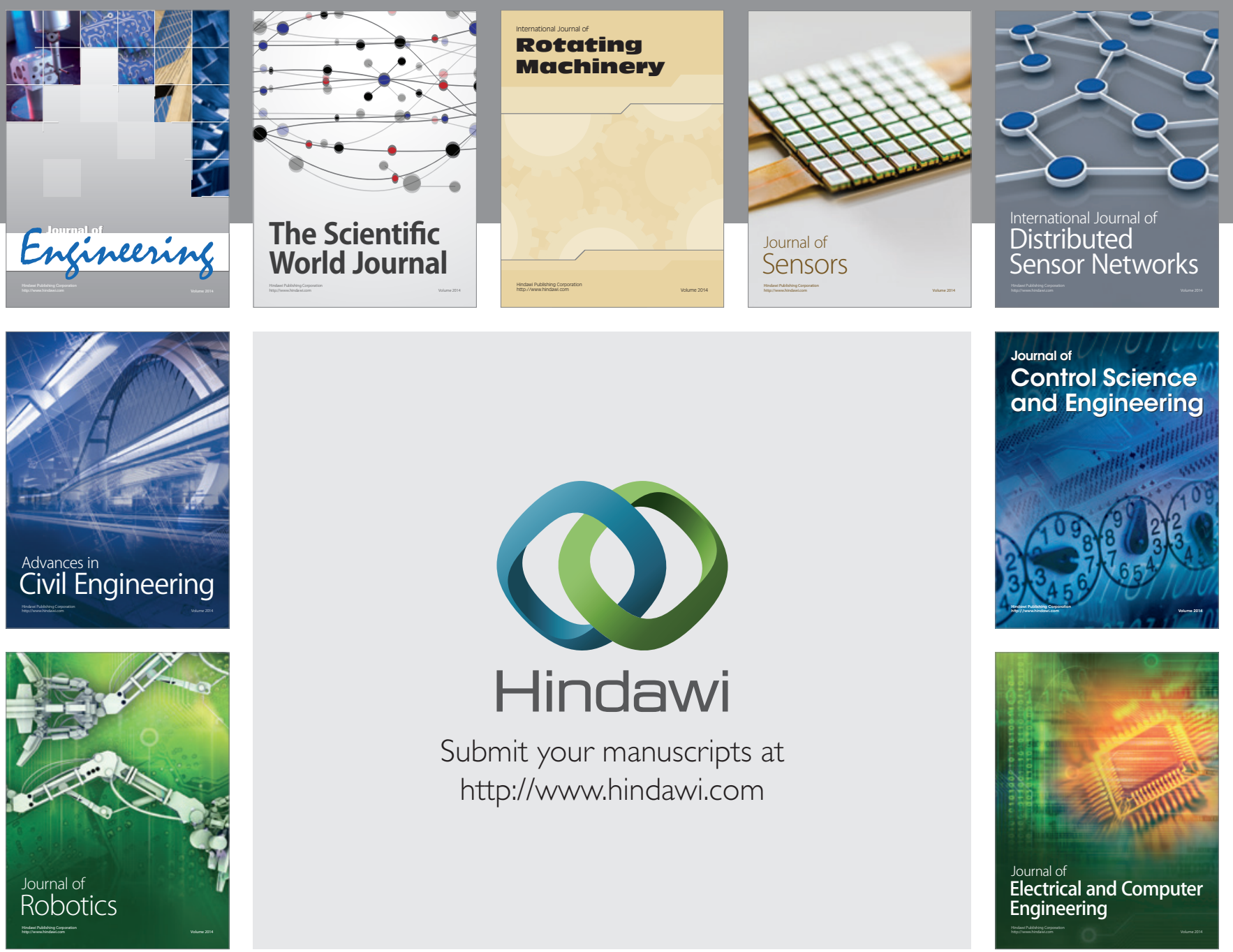

Submit your manuscripts at

http://www.hindawi.com
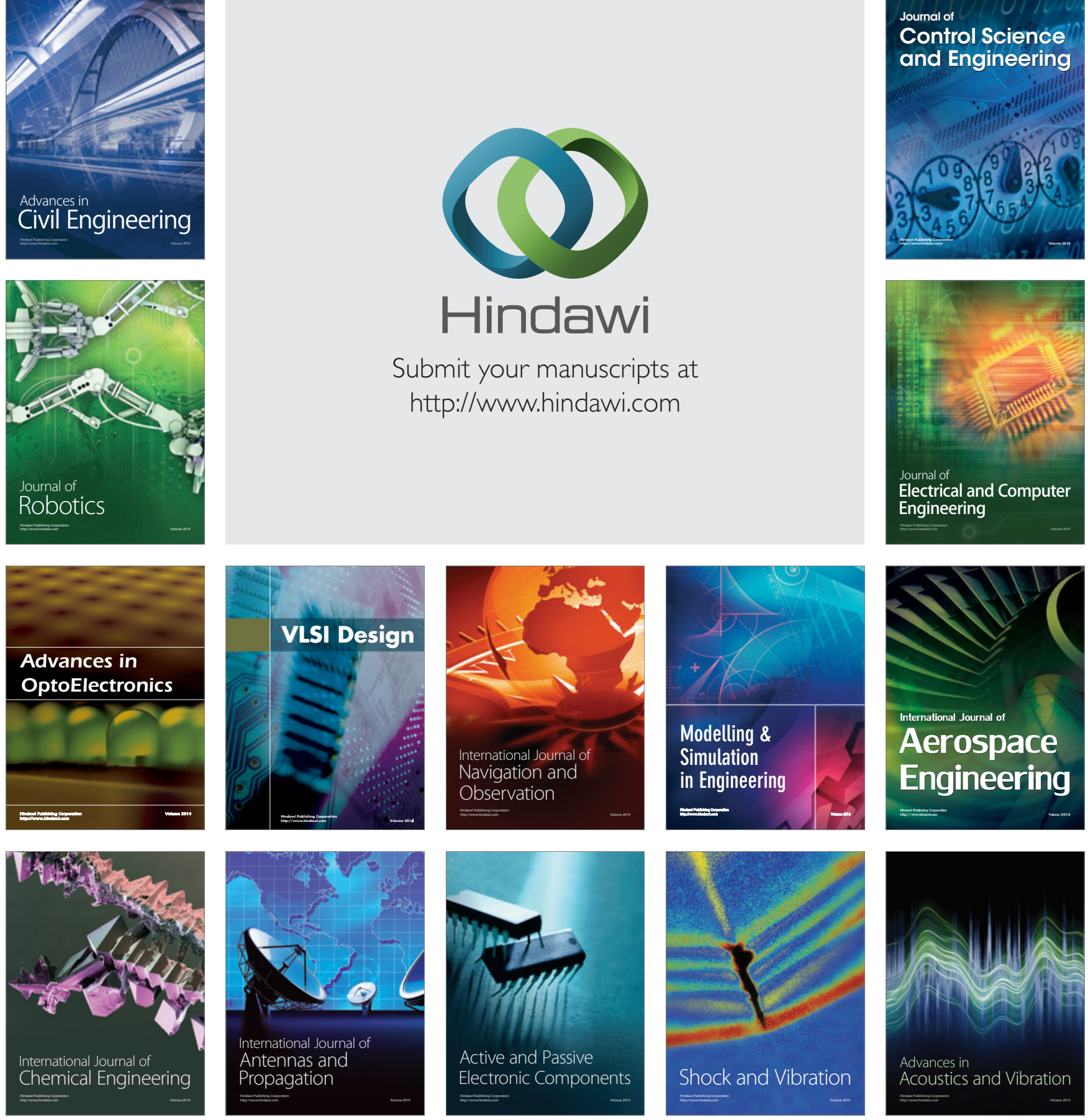